\title{
BMJ Open Exploring factors impacting early childhood health among Aboriginal and Torres Strait Islander families and communities: protocol for a population- based cohort study using data linkage (the 'Defying the Odds' study)
}

Bridgette McNamara, ${ }^{1}$ Lina Gubhaju, ${ }^{1}$ Louisa Jorm, ${ }^{2}$ David Preen, ${ }^{3}$ Jocelyn Jones,${ }^{4}$ Grace Joshy, ${ }^{5}$ Carrington Shepherd, ${ }^{6}$ Daniel McAullay, ${ }^{7}$ Sandra Eades, ${ }^{1}$ the Defying the Odds project investigators.

To cite: McNamara B Gubhaju L, Jorm L, et al. Exploring factors impacting early childhood health among Aboriginal and Torres Strait Islander families and communities: protocol for a population-based cohort study using data linkage (the 'Defying the Odds' study). BMJ Open 2018;8:e021236. doi:10.1136/ bmjopen-2017-021236

- Prepublication history and additional material for this paper are available online. To view these files, please visit the journal online (http://dx.doi. org/10.1136/bmjopen-2017021236).

Received 19 December 2017 Accepted 5 January 2018

Check for updates

For numbered affiliations see end of article.

Correspondence to Dr Bridgette McNamara; bridgette.mcnamara@baker. edu.au

\section{ABSTRACT}

Introduction Empirical evidence on family and community risk and protective factors influencing the comparatively high rates of potentially preventable hospitalisations and deaths among Aboriginal and Torres Strait Islander infants and children is limited. As is evidence on geographical variation in these risks. The 'Defying the Odds' study aims to explore the impact of perinatal outcomes, maternal social and health outcomes and level of culturally secure service availability on the health outcomes of Western Australian (WA) Aboriginal infants and children aged $0-5$ years.

Methods and analysis The study combines a retrospective cohort study that uses state-wide linked health and administrative data from 12 data sources for multiple generations within Aboriginal families in WA, with specifically collected survey data from health and social services supporting Aboriginal families in regions of WA. Data sources include perinata/birth registration, hospital, emergency department, mental health services, drug and alcohol service use, mortality, infectious disease notifications, and child protection and family services. Multilevel regression models will be used to examine the intensity of admissions and presentations, mortality, intensity of long stays and morbidityfree survival (no admissions) for Aboriginal children born in WA in 2000-2013. Relationships between maternal (and grand-maternal) health and social factors and child health outcomes will be quantified. Community-level variation in outcomes for Aboriginal children and factors contributing to this variation will be examined, including the availability of culturally secure services. Online surveys were sent to staff members at relevant services to explore the scope, reach and cultural security of services available to support Aboriginal families across selected regions of WA. Ethics and dissemination Ethics approvals have been granted for the study. Interpretation and dissemination are guided by the study team's Aboriginal leadership and reference groups. Dissemination will be through direct feedback and reports to health services in the study and via scientific publications and policy recommendations.
Strengths and limitations of this study

This Aboriginal-focused data linkage and health services research concentrates on what is working to improve early childhood health, and to identify persisting areas of need, within Aboriginal families and communities alone (without comparison to non-Aboriginal).

- The large, retrospective cohort-constructed with family linkage information and whole-of-population linked health and administrative data-will allow exploration of factors in multiple generations of Aboriginal and Torres Strait Islander families across the entire state of Western Australia, with minimal selection bias or responder burden.

- The linked data analysis is strengthened by the contextual information, obtained via survey, on the local availability of culturally secure services to support Aboriginal families.

- The use of routinely collected data involves some limitations. However, the use of multiple data sources will improve Aboriginal identification and sensitivity of risk factor detection within the data.

\section{INTRODUCTION}

If the health of a nation is judged on the health of its most vulnerable population, Australia can be considered to fare poorly by most standards. Persistent and substantial health inequalities are a feature of aggregate health statistics, with Aboriginal children experiencing significantly increased odds of poor perinatal outcomes, and potentially preventable diseases and injury at a state-wide and national level. ${ }^{1-4}$ While highlighting the need for action on a whole, hidden behind these aggregate statistics are wide variations in the 
health outcomes of Aboriginal people themselves-with many children, families and communities achieving good health despite being 'high risk'. Without greater examination of the variation to understand the complex pathways and risk profiles contributing to these health outcomes, it is unlikely that effective solutions will be developed to improve health at a population level. Determining what helps children in disadvantaged communities at high risk to defy the odds and thrive is essential; namely, what is it in the family and community environments that help children avoid serious morbidity and mortality in the earliest years, who are the children at greatest risk of serious ill health and death, and what are the short and long-term modifiable risk factors that could be addressed to improve their health trajectories?

\section{Largely preventable burden of early childhood morbidity and mortality among Aboriginal infants and children}

A large proportion of the excess burden of morbidity experienced by Aboriginal and Torres Strait Islander infants and children is potentially preventable. In the first year of life, the proportions of Aboriginal infants born in Western Australia (WA) in 2010 and 2011 who presented to emergency departments $(71 \%)$ or who were admitted to hospital at least once $(44 \%)$ were twice that of non-Aboriginal children (42\% and 29\%, respectively). Moreover, $10 \%$ of Aboriginal infants were admitted three or more times during the first year of life compared with only $3 \%$ of non-Aboriginal infants. ${ }^{3}$ Similarly across childhood, in New South Wales, rates of potentially avoidable hospitalisations were 1.7 times higher for Aboriginal children aged 0-14 years than non-Aboriginal children. ${ }^{2}$ Typically, ambulatory care-sensitive conditions such as acute bronchiolitis, gastroenteritis, asthma, dental conditions and acute upper respiratory tract infections are responsible for the greatest proportion of admissions overall ${ }^{235}$ and occur at significantly greater rates among Aboriginal children than other Australian children. ${ }^{2}$

\section{Persistent sociodemographic inequalities}

This burden of ill health is occurring in the context of, and is likely due in large part to, the comparatively higher levels of social disadvantage experienced by many Aboriginal Australians. Socioeconomic and educational inequalities persist as a legacy of the centuries of discriminatory state and national policies and legislation, ${ }^{6}$ and continued structural and institutional marginalisation of Indigenous culture and knowledge systems. ${ }^{6}$ Intergenerational trauma resulting from the forced degradation of language, land-based cultural traditions and family structure that occurred in the centuries following colonisation of Australia by Europeans also continues to impact current generations and increase social risk factors among many Aboriginal families and communities. ${ }^{7}$ National data show lower levels of educational attainment and higher rates of unemployment among Indigenous Australians than the total Australian population. ${ }^{8}$ Social risk factors such as family violence and parental drug or alcohol problems are also more prevalent among Aboriginal and Torres Strait Islanders-for example, rates of hospital admissions for interpersonal violence in 2004 in WA were over 10 times those among non-Indigenous Australians, with Aboriginal women most at risk. ${ }^{9}$ During pregnancy, drug and alcohol use is more prevalent among Aboriginal mothers. ${ }^{10-13}$

\section{Importance of early life health outcomes for lifelong health}

The rapid and extensive nature of the development that occurs during infancy and early childhood means that it is a particularly 'sensitive' period, with potential for stronger, longer-lasting effects via biological or social and emotional pathways than in later periods of life. ${ }^{14} 15$ There is evidence for clear associations between health outcomes at these early time points, and later life academic performance, employment, health and wellbeing and life expectancy. ${ }^{16}$ Therefore, the importance of improving early childhood health outcomes to achieving lifelong health for this generation and future generations cannot be underestimated.

\section{Access to needs-based, culturally secure services}

In addressing the disparities in health between Aboriginal Australians and non-Aboriginal Australians, it is recognised that there is a greater need to provide appropriate, culturally secure services that address the priorities of Aboriginal people and work effectively across a range of sectors with Aboriginal community leadership. ${ }^{17}$ Improving early childhood health is a recognised priority of Aboriginal communities and the Australian government ${ }^{18}$; however, evidence on the ways in which to best achieve this is still emerging. Improved development of and direction of resources towards quality programmes and services that are effective for Aboriginal people requires greater understanding of the complex pathways impacting childhood health among Aboriginal Australians, including a better understanding of the diversity of risk contexts and outcomes among Aboriginal Australian families and communities across the geographical spectrum of Australia and the factors responsible for this diversity.

\section{Importance of examining childhood health risk in the context of family and community}

Community is central to the conceptualisation of health among Aboriginal and Torres Strait Islander peoples; health is a holistic notion, encompassing 'not just the physical well-being of an individual but refers to the social, emotional and cultural well-being of the whole community' and aspects of spirituality and connection to land. ${ }^{19}$ These conceptions are consistent with the broader human development literature, which highlights that children have many spheres of influence. ${ }^{20} 21$ Factors at the family, community, regional and national levels all influence individual health outcomes, yet few studies have quantified these relationships in Aboriginal populations. During infancy and the earlier years of 


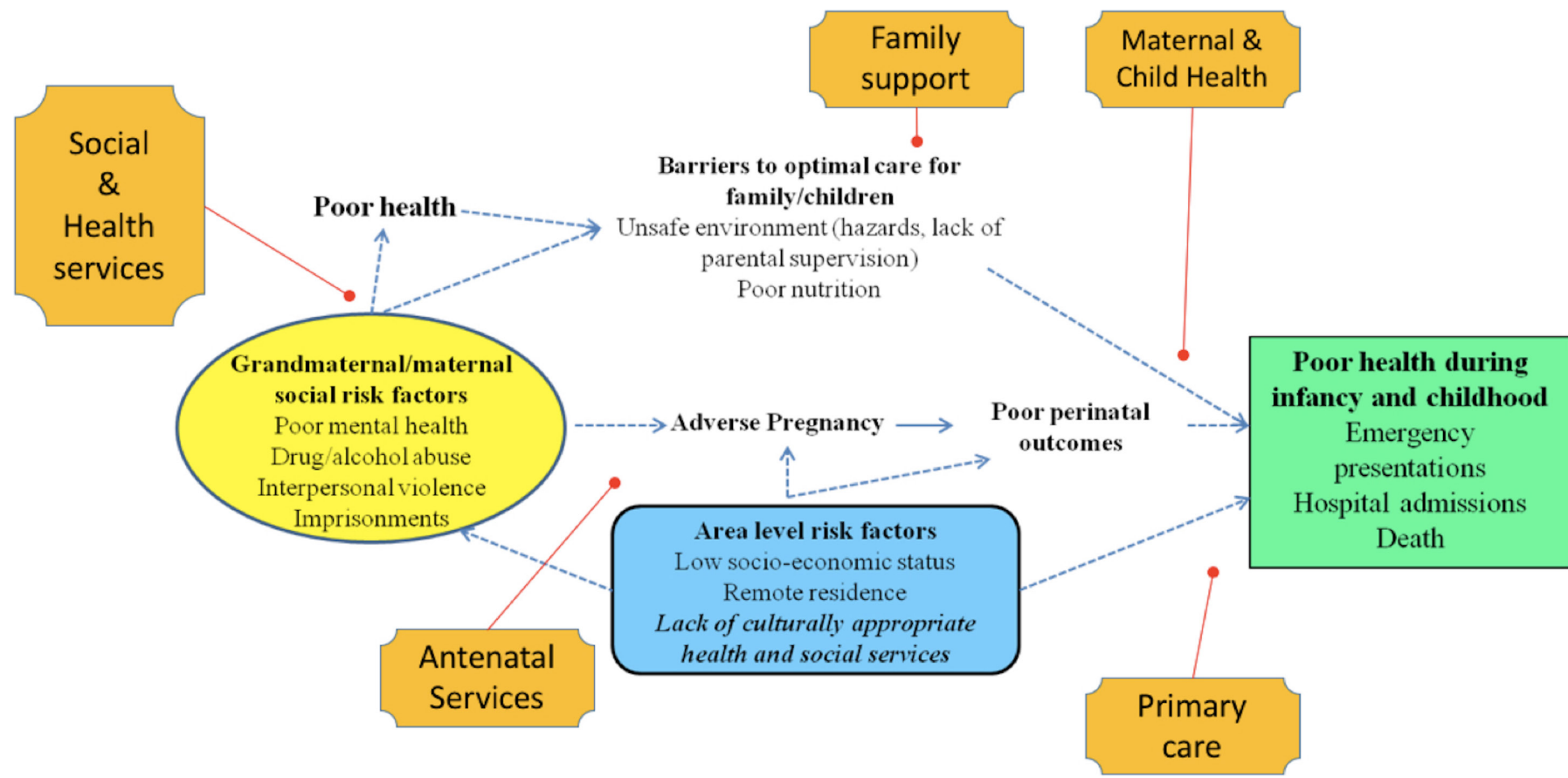

Figure 1 Basic conceptual model of potential influences of grand-maternal/maternal social risk factors on health outcomes of children in infancy and early childhood and opportunities for culturally secure services (presented in orange banners) to intervene in these risk pathways.

childhood, the direct relationships and care environment provided by family are found to be paramount to healthy child development. ${ }^{21}$ Factors affecting the health and social well-being of mothers are likely to be particularly important. In addition to the direct impacts of maternal health and well-being on fetal development during gestation, mothers are typically the principal carers of young children in Aboriginal families (over 92\% of Aboriginal children aged $0-3$ years in $\mathrm{WA}^{22}$ and other states) ${ }^{23}$ and therefore significantly determine the care environment experienced by the child (proposed conceptual model in figure 1). Gaining a more nuanced understanding of the way that maternal social and health risk factors relate to health outcomes of Aboriginal children, including early cognitive and language development and emotional and behavioural regulation, is likely to support an improvement in childhood health and well-being.

\section{Limited population-based evidence to support programme/ service development}

There is currently limited population-based evidence on risk factors for infant and early childhood mortality and morbidity among Aboriginal children. Our systematic search in Medline, of peer-reviewed literature with childhood hospitalisations, emergency presentations or deaths as the study outcomes identified 104 quantitative empirical studies. The majority of these primarily considered individual-level risk factors such as age, gender, birth weight, prematurity and vaccination status. Only a handful of studies examined family/maternal risk characteristics, and these were largely limited to an examination of maternal age and parity (table 1). Most studies that considered geographical variation were limited to urban/ non-urban geographical dichotomies (table 1, online supplementary information file 1 details search terms used). Furthermore, robust population-based research investigating differences in rates and determinants within the Aboriginal population itself are currently lacking; studies almost universally compare Aboriginal rates with those in the non-Aboriginal population and provide little information separately around the risk and protective factors for Aboriginal Australians. While comparisons to non-Aboriginal Australians can be useful to highlight specific disparities in treatment opportunity and for measurement of progress towards health equality in a global sense, sole use of this type of analysis frequently relegates the Aboriginal Australians to deficit narratives without real opportunity to look at what works to improve health outcomes by examining variation in health outcomes within Aboriginal communities. ${ }^{24} 25$

Research that moves beyond simplistic models using individual risk factors and includes an examination of factors from the family environment (including intergenerational risks), the wider community, and access and use of health and family services among the Aboriginal population is crucial to improving health outcomes among Aboriginal Australians.

\section{HOW CAN DATA LINKAGE STUDIES WITH FAMILIAL RELATIONSHIPS FILL THIS GAP?}

The development of data linkage systems in a number of Australian states and territories in recent years has 


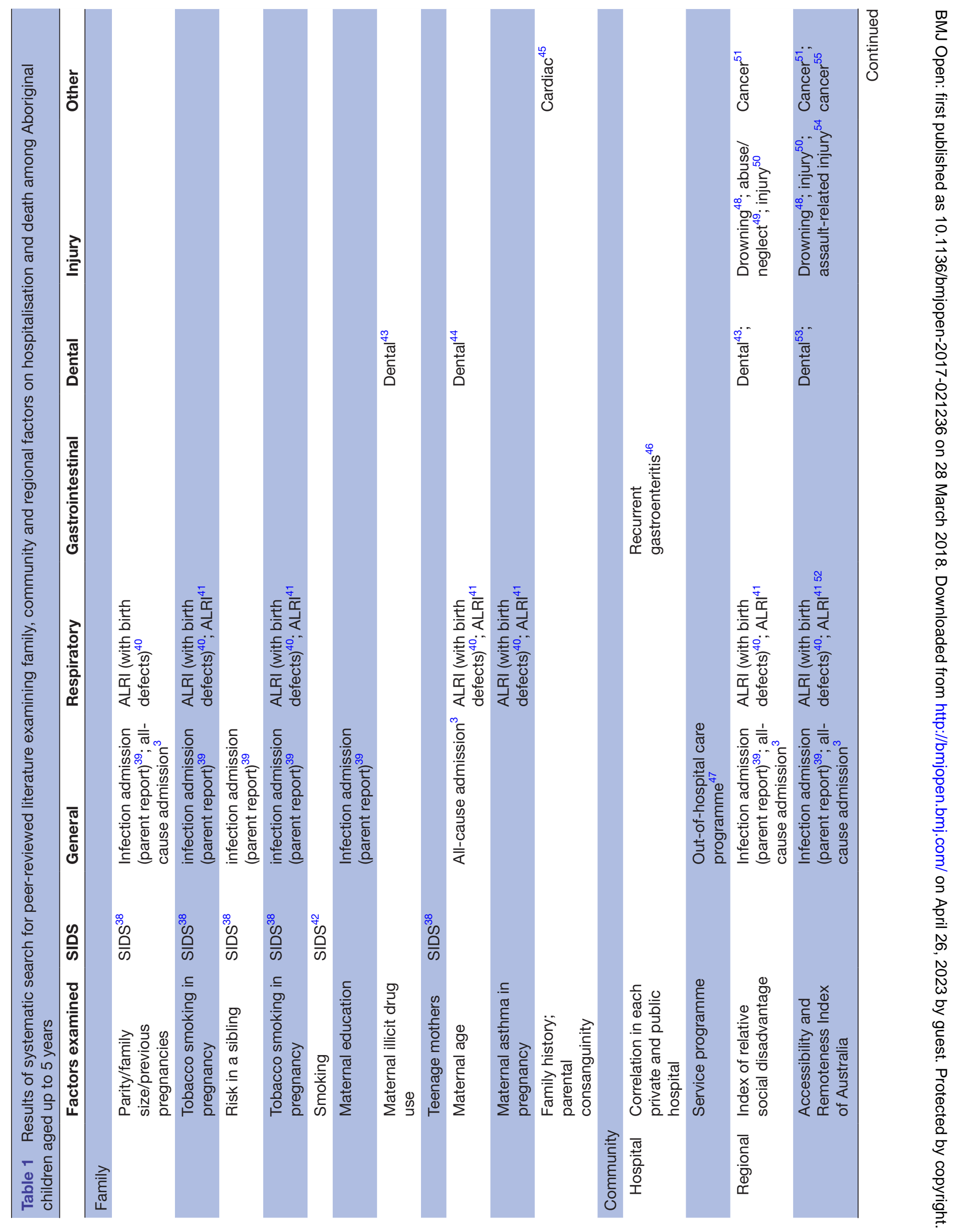


meant that routinely collected data from a variety of different health and social sources can be used to answer many complex questions. Family linkages are a critical component of these data systems, and where available they enable an examination of the way that exposures and health outcomes of previous generations affect health outcomes of the current generation of children. The Defying the Odds study has been designed as a retrospective cohort study of all Aboriginal and Torres Strait Islander children born in WA between 2000 and 2013, and their families. The study will use family linkage information from the Western Australian Data Linkage System (WADLS) to quantify the effect of a range of health and social risk factors for multiple generations (in mothers, grandmothers and other family members) to the health of these Aboriginal children in the first 5 years of life. The data linkage studies will be complemented with health services research with specifically collected data from existing health and social services on the scope, reach and cultural security of these services. Defying the Odds aims to provide currently lacking knowledge to inform effective service development and resource allocation to support families and to improve infant and child health outcomes.

The study will examine the following research questions:

1. What are the risk and protective factors for Aboriginal infant and childhood morbidity and mortality during the perinatal period and from maternal and grand-maternal social and medical history?

2. Is there geographical variation in Aboriginal infant and childhood morbidity and mortality? If so, what are the specific community-level characteristics that are impacting the disease burden?

3. What has been the scope, reach, quality and cultural security of maternal and child health/social services in WA from 2000 to 2013?

4. What are the enablers and barriers encountered by health/social services to providing high-quality care to support Aboriginal families?

5. What is the relationship between health/social services and Aboriginal infant and child health outcomes? Importantly, what has been the impact of health and social services in Western Australia on infant and childhood mortality and morbidity after taking into account risk factors during the perinatal period and from the maternal and grand-maternal social and medical history?

\section{METHODS AND ANALYSIS}

\section{Study design, setting and population}

Defying the Odds uses mixed methods, with two components: a total population-based retrospective cohort study using linked administrative health data, supplemented with a health services research component involving service mapping and a quantitative online survey.

The study population is Aboriginal and Torres Strait Islander families in WA. Around $13.1 \%$ of the estimated 
669881 national Aboriginal and Torres Strait Islander population reside in WA $(3.8 \%$ of the total 2.4 million WA residents), ${ }^{26}$ with $34 \%$ residing in major cities, $25 \%$ in regional areas and $41 \%$ in remote/very remote areas of the state. ${ }^{26}$ WA has a number of advantages in terms of a study setting, with potential for the findings to be generalisable to the broader Australian population. It has among the lowest out-of-state migration across the Australian States and Territories, which is beneficial for longitudinal follow-up. WA has also been empirically shown to be representative of the wider nation as a whole with it being closest to the average of the eight Australian States and Territories with respect to median age, gender distribution, rural to remote residential ratio, proportion of low-income earners, proportion of disabled people and per capita health expenditure, hospital bed supply, Medicare and Pharmaceutical-Benefits-Scheme payments. ${ }^{27}$

\section{Study cohort and family connections}

The cohort will comprise all Aboriginal and/or Torres Strait Islander children born from 2000 to 2013 residing in WA at the time of birth. Identification of Aboriginal and Torres Strait Islander children will use the Indigenous indicator provided by the WA Data Linkage Branch (DLB). ${ }^{28}$ This indicator uses a multistage median approach across the range of core datasets to produce a single indicator of Indigenous status for each individual. In this study, the indicators of mothers, fathers and the children themselves will be used to identify our cohort children. A child will be included in the cohort if they or their mother or father are identified as Aboriginal. However, we will also conduct sensitivity analyses to examine other approaches to identification, including considering identification of maternal and paternal grandparents of the children. The potential for improving identification among parents and grandparents through the use of information from birth-related records of all of their children as an additional source of identification may also be explored.

\section{Data linkage and extraction}

Data linkage will be conducted within the WADLS, operated by the WA DLB. The WADLS is one of only a small number of comprehensive whole-population data linkage systems in the world and constitutes a powerful source for conducting health research on an entire population within an Australian setting. ${ }^{29}$ Computerised probabilistic matching is used to create linkages within and between a variety of health and other administrative datasets. Matching procedures are based on exact, partial and/or similarity matches between demographic and other identifiers. An evaluation of linked chains (which may contain over 2000 links) estimated that less than $0.3 \%$ of chains contained one or more incorrect links. ${ }^{29} 30$

Family relationships will be determined using links created by the WA Family Connections Genealogical
Project, which has created a supplementary set through the WADLS data collections that identify parentoffspring relationships by linked information from birth registrations and midwives' notifications. The genealogical linkages contain information about the vast majority of the WA population; as of 2007 , only $6 \%$ of the population did not have genealogical links (due to birth outside of WA, lack of contact with any of the data systems and incomplete registrations). ${ }^{31}$

Data have been extracted from WADLS using the broad extraction criteria for the cohort of any individual who has ever been identified as Aboriginal and/ or Torres Strait Islander in any record of the requested datasets or who has a parent, full sibling or grandparent (maternal and paternal) who has ever been identified as Aboriginal and/or Torres Strait Islander in any of the requested datasets. These broad criteria were employed to ensure that we have a complete extract for any children who could possibly be identified as Aboriginal from all requested data sources, which we will then narrow down using the methods of Aboriginal identification methods and sensitivity analysis described in the study cohort description above. For individuals in the cohort extraction, we are also examining records of their full siblings, half-siblings, parents and grandparents. Using these data, we will construct linked Aboriginal families from root mothers or grandmothers of two-level and three-level multigenerational families, and these families will be mapped to communities and service areas by the WA DLB using geocoded data.

\section{Data sources and quality}

The data sources to be examined are shown in figure 2 . Data are from statutory collections (routine collection required by law). The primary sources of outcome data have been shown to be highly reliable. A review of linked data from the Hospital Morbidity Data Collection (HMDC), mental health and mortality data for 1990-1994 found no instance of a missing principal diagnosis for any record. The least complete variable was marital status, with only nine cases missing $\left(99.995 \%\right.$ complete). ${ }^{29}$ There are 21 different quality checks built into the provision of data from hospitals and periodic audits of random selections of hospital-assigned codes are undertaken. A recent review of the Emergency Data Information system (one of four information systems included in the Emergency Department Data Collection (EDDC) used to collect patient data from metropolitan public hospitals and one regional hospital in Bunbury) found that all variables entered into the electronic patient admission system were at least $96 \%$ complete. Of those variables entered directly by clinical staff, all but two variables were above $99 \%$ complete. The percentage of invalid entries in all fields was less than $0.1 \% .^{32}$ Further information around the completeness, sensitivity and specificity will be sought where appropriate. 


\section{DATA SOURCES \\ - Birth Registrations 1974 - 2016 \\ - Death Registrations 1969-2016 \\ - WA Infant, Child, Youth Mortality database 1980-2011 \\ - Midwives' Notification System (MNS) 1980-2014 \\ - WA Register of Developmental Anomalies 2000-2016 \\ - Hospital Morbidity Data Collection (HMDC) 1970-2016 \\ - Emergency Department Data Collection (EDDC) 2002-2016 \\ - Mental Health Information System (MHIS) 1966-2016 \\ - WA Notifiable Infectious Diseases Database (WANIDD) 1990-2016 \\ - Child protection and Family Services Data 2000-2017 \\ - Drug and Alcohol Office data 1974-2005 \\ - ABS Census Data $(1996,2001$, 2006, 2011) \\ - Service mapping data \\ - Health and Social Service Survey Data (collection ongoing)}

Mortality and Morbidity outcomes in first five years of life Deaths, hospitalisations/Emergency presentations, Morbidity-free survival (no admissions)
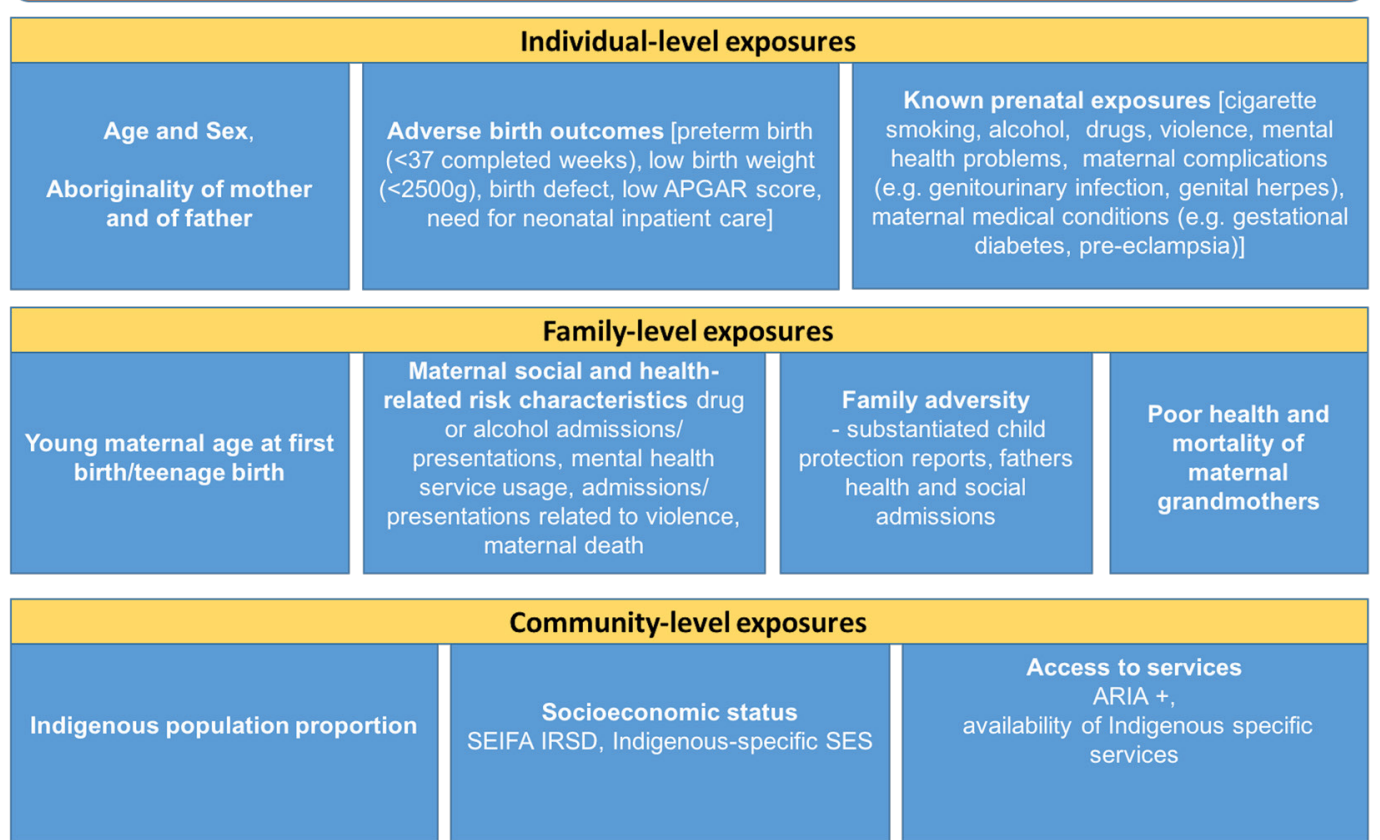

Figure 2 Summary of data sources, outcomes and exposures for the Defying the Odds study. ARIA, Accessibility and Remoteness Index of Australia; SEIFA ISRD, Socio-Economic Indexes for Areas Index of Relative Socio-economic Disadvantage.

Quantifying the impacts of family and community risk and protective factors to early childhood health outcomes (research questions 1 and 2)

Multilevel regression models will be used to quantify contributions of individual-level, family (maternal)-level and community-level variables relating to the social and health environment to mortality and morbidity outcomes among Aboriginal infants and children in WA from 2000 to 2013.

\section{Outcomes}

The following early-life health outcomes will be examined:

1. Stillbirths-defined as baby born with no signs of life at or after 20 weeks' gestation. ${ }^{33}$

2. All-cause infant and child mortality-defined as the death of a child less than 5 years of age. ${ }^{34}$ Survival/ mortality risk among infants/children will be calculated as days until death from birth or beginning of the age category.

3. All-cause hospital admissions-(a) intensity of hospital admissions or emergency presentations, calculated as the number of separate continuous periods of stay (ie, subsequent transfer from one hospital to another for the same condition will be counted as a single hospitalisation) and number of emergency presentations for each person per year of follow-up. Use of emergency presentation will capture morbidity that is not severe enough to warrant inpatient treatment (particularly important for injury and some infections). (b) Number of long stays-calculated as the number of continuous hospital stays of greater than 7 days per person-year of follow-up. This outcome reflects the frequency of serious morbidity. (c) Total bed dayscalculated by summing the lengths of stay for each person per year of follow-up. This outcome reflects the overall duration of serious morbidity requiring inpatient care. (d) Morbidity-free survival—calculated as a binary outcome, designating where there has been no condition serious enough to warrant inpatient treatment. This positive outcome will allow investigation of the protective characteristics of individuals, mothers and areas where children are 'defying the odds'.

4. Cause-specific hospital admissions-the principal categories to be investigated are infections (localised and systemic) defined as any condition that is likely to have been caused by an infectious agent (bacteria, viruses or parasites); external (injuries or poisoning). The following International Statistical Classification of Diseases and Related Health Problems, Tenth Revision, Australian Modification codes will be used for classification: A00-B99, J00-J99, L00-L08 (Infections), V01-Y98 and S00.0-T98.3 (External).

\section{Explanatory variables}

Figure 2 presents explanatory factors and relevant data sources. Regression models will contain three levels (individual, family (maternal) and community). The effect of factors at each of these levels will be quantified. Individual-level variables include basic demographic variables, birth outcome variables and variables indicating known prenatal exposures based on the data (including smoking 
in pregnancy, pregnancy complications and maternal medical conditions). At the family level, maternal health and social risk factors are of particular interest-exposures such as maternal history of drug and alcohol abuse, mental health problems and exposure to interpersonal violence during the study period and across the life course will be examined. The health of maternal grandmothers will also be explored to examine the effects of intergenerational risk on early childhood health. Other family-level factors such as indicators of family dysfunction (child protection notifications) and paternal health will be examined in later models. Community-level factors will examine how the proportion of Aboriginal and Torres Strait Islanders living in particularly small geographical regions, socioeconomic circumstances and importantly how remoteness and local access to Indigenous specific services impact on childhood health outcomes.

\section{Statistical analysis}

Mortality and morbidity outcomes of the cohort will be assessed using data from the HMDC, EDDC and the mortality database. All-cause mortality risk/survival of the cohort will be modelled using multilevel Cox (proportional hazards) regression analysis. Morbidity outcomes will be analysed in three age categories: neonatal infant (0-28 days), post-neonatal infant (29 days to $<1$ year) and childhood ( 1 year up to $<5$ years). Separate multilevel regression models will be constructed for each outcome in each age category. Number of hospital admissions and number of long hospital stays will be modelled using multilevel Poisson regression. Models will be corrected for possible overdispersion of data, either by using an adjustment parameter in the Poisson model or by fitting a negative binomial regression model. In the case of a highly right-skewed distribution of the number of admissions beyond the first, or the number of readmissions, zero-inflated Poisson or multinomial models will be fitted. Total bed days will be modelled using multilevel regression models, applying a logarithmic transformation to the total number of bed days as appropriate, and morbidity-free survival (no hospital admissions) will be modelled using logistic regression. Health outcome risks will be considered at an individual, family (maternal) and community level. Assessment of the variation in these outcomes at the different levels will allow us to look at how risk is clustered at each level and then quantify the extent to which this is accounted for by our key exposure/risk variables. Bayesian disease-mapping techniques will be used to test for geographical variation in the outcomes beyond the level of communities (ie, patterns of similar risk between neighbouring communities).

\section{Missing data}

Outcome data are complete for all Aboriginal children to be included in the study cohort, that is, where family linkages are known. Comparative descriptive statistics for children missing family linkage information will be presented. Missing covariate data will be addressed through the use of 'missing' categories in analyses and sensitivity analysis using multiple imputation as appropriate.

Analysis to assess the availability of relevant culturally secure services (research questions 3, 4 and 5)

Availability of accessible, quality and culturally secure healthcare is understood to greatly impact on health outcomes of Aboriginal and Torres Strait Islander Australians, ${ }^{35}$ although large-scale empirical studies are scarce. Defying the Odds will use a combination of publicly available existing literature and interviews with key informants to gather data on the scope, target population and reach of existing maternal, child health and family services across regions of WA from 2000 to 2013. The study will include primary care and community health organisations that have a stated focus on Aboriginal health among Aboriginal community-controlled health services, Government healthcare, community health and general practice care, also public health (eg, health promotion and education), hospital services, specialised health services (eg, mental health, alcohol and other drug treatment) and other large interventions/programmes. In each of the above, the quality and cultural security of these services from a staff perspective will be examined in the following areas: (1) maternal and child health, (2) family support, (3) domestic violence, (4) drug and alcohol, (5) mental health, (6) prison health and post-release services, and (7) legal services. A scoping review will identify gaps in the literature relating to existing studies on the impact of health services on Aboriginal infant and child health outcomes. Four regions of Western Australia have been selected based on previous data on the extent of the variation of infant health outcomes and lack of current research into service provision within these areas (Perth Metropolitan, South West, Great Southern and Goldfields-Esperance). Figure 3 shows a map of the regions to be included in the study.

Data on the scope, target populations, reach and cultural security of health services will be collected using two online surveys. The first survey will be completed by a participant in an administrative/managerial role and collect data on the characteristics of a service (including opening hours, numbers of staff and patients, fees and transport, and aspects of cultural security). The second survey will be completed by around five staff from the health service and ask their opinion on the quality and reach of the service, facilitators and barriers to effective care and on aspects of cultural security of the service. Initial contact with the health and social services to be recruited into the study will be made by telephone, and an Aboriginal study investigator will then visit services that showed an interest in participating in the study to meet staff and present the overall study objectives. Key informants will be asked if they would like to participate in the online survey, and written/online 


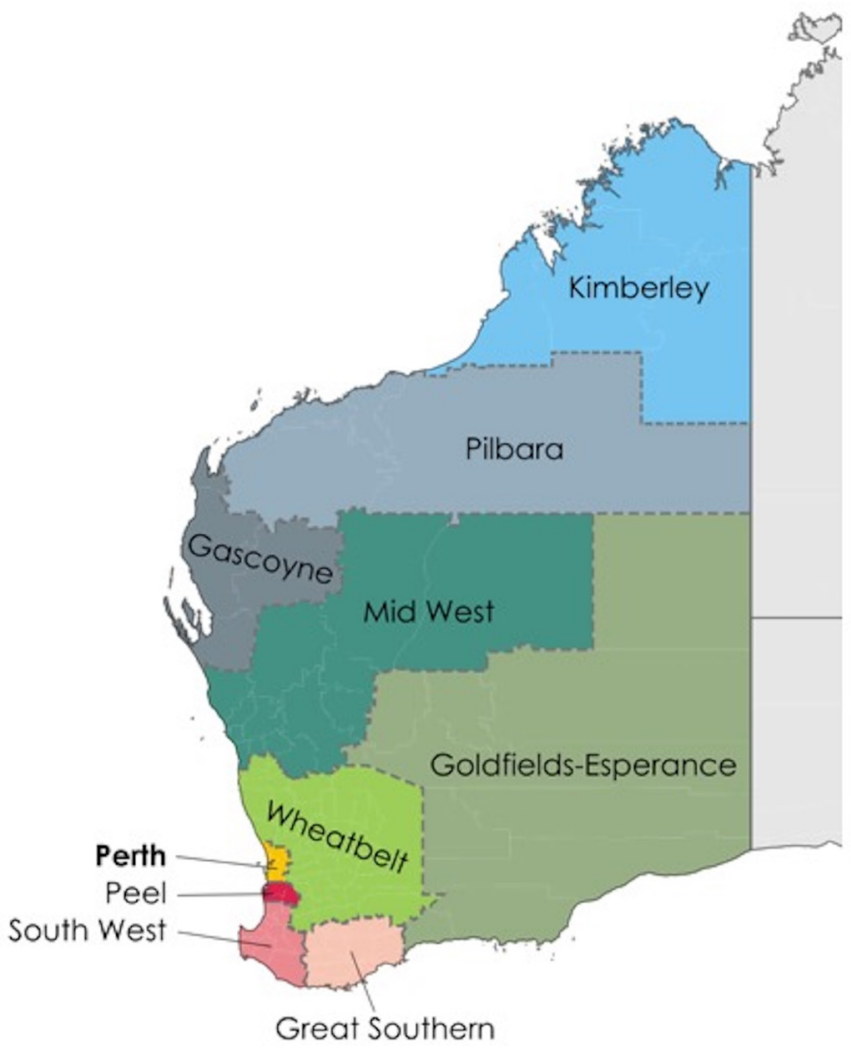

Figure 3 Regions of Western Australia. The regions to be studied as part of assessment of access to culturally secure services to support Aboriginal and Torres Strait Islander families are Perth, South West, Great Southern and Goldfields-Esperance. (Credits for the image to Toby Hudson. This image is based on data from the Australian 2011 Census of Population and Housing compiled by the Australian Bureau of Statistics.)

consent will be obtained. Responses to the survey will be kept anonymous and group results will be presented in a way that protects the confidentiality of the individual staff and services. Information on services that were available between 2000 and 2013 but have since ceased is sought from public resources, annual reports and through a question in the survey around previous programmes within currently operational services.

\section{Cohort size and statistical power}

The study is highly powered; in conservative power calculations, with over 17000 children, the study would have $80 \%$ power to detect a HR of at least 1.1 (assuming median survival time of 5 years among unexposed) and ORs of at least 1.2 (for exposures of $20 \%$ or more) at a 5\% significance level. A preliminary analysis of the extracted data indicates the study cohort comprises over 31000 Aboriginal children born to more than 15000 mothers.

\section{Ethics and dissemination}

The project has ethics approval from Western Australian Aboriginal Health Ethics Committee (\#609), WA Department of Health Human Research Ethics
Committee (HREC) (\#2015/30), WA Country Health Services HREC (\#2016/17) and Alfred Health HREC (\#268/15). Interpretation and practical implications of research will be guided by the Aboriginal reference group for the project and discussions with Aboriginal community health organisations involved in the project. Outputs will include scientific papers, and publications / reports of findings and recommendations directed as a number of audiences including policy-makers, health service providers and community organisations. Reports specific to local regions of WA will be produced and provided to community groups and services.

\section{DISCUSSION}

Given the importance of the first years of life to lifelong health, it is vital to understand the factors contributing to the early burden of disease among Aboriginal people and thereby to identify ways to enable individuals to 'defy the odds', and thrive. The innovation of the Defying the Odds study lies in examining the context out of which health risks arise in both the family and community setting for an entire population of Aboriginal people, and with a focus entirely on Aboriginal and Torres Strait Islander Australians. It will be the first to examine the contributions of family and community risk factors to morbidity and mortality in Aboriginal children and to look for common risk pathways across a range of conditions at a total-population level. By gathering data on the services that were available to Aboriginal people during the study period and particularly on the cultural security of these services, the project will provide a unique opportunity to assess their relationship to health outcomes across WA communities. Mapping the availability of cultural security of services to geographical variations in outcomes and key risk factors derived from the linked data analysis provides a powerful method to evaluate the way existing programmes are meeting current needs and where greater resources are needed.

\section{Strengths}

A major strength of this study is that it is Aboriginal-focused with strong Aboriginal leadership in the investigator team and an Aboriginal reference group. The study looks to examine pathways to health within the Aboriginal and Torres Strait Islander population of WA without a focus on comparisons with non-Indigenous Australians. The use of deidentified whole-of-population data presents a number of benefits compared with traditional prospective cohort studies including minimising selection bias, minimal loss to follow-up, ensuring participant privacy, avoiding time lags in results associated with prospective cohort studies, avoiding reliance on self-reported data (which are prone to recall and ascertainment biases) and cost-effectiveness. The large size of the data linkage cohort allows this research to support more in-depth cohort studies by providing 
estimates and context for these studies. Such estimates provide vital evidence to inform policy and state-based strategy; having data for Aboriginal peoples themselves is essential for empowering communities to advocate for their needs and for ensuring that funding and resources are allocated in a way that strives for equity in health outcomes. The examination of geographical variation of health outcomes and risk by smaller region and the mapping of existing services to the observed need will allow a broad perspective highlighting areas of unmet need as well as areas that have demonstrated substantial health gains and effective service provision. The use of routinely collected data, when used in conjunction with strict privacy and confidentiality provisions and community partnership in the direction of the research, also greatly reduces respondent burden for Aboriginal communities.

\section{Limitations}

The use of routinely collected data, collected for administrative purposes, does have limitations. There is known underestimation/uncertainty in identification of Aboriginal people in routinely collected data, coupled with improving of identification over time, thus the misclassification is not random. ${ }^{36}{ }^{37}$ To address this, our study will use the DLB Indigenous status flag that identifies Aboriginal and Torres Strait Islander children from records in multiple datasets for each individual, ${ }^{28}$ and we will also use information on the Indigenous status of the child's mother, father and siblings to further improve the classification. The use of time covariates will be used in analysis as appropriate. Further, the cohort approach of this study means that any under-ascertainment will affect the numerator and denominator to the same degree. Under-ascertainment of key social risk factors (eg, drug and alcohol, mental health and violence) also needs consideration. ${ }^{12}$ It is clear that this study will capture heavy use and serious conditions that have warranted recording in hospital records. We will limit the under-ascertainment through the use of multiple data sources for the classification of risk, the use of emergency data to capture conditions not serious enough to warrant inpatient admission and through examination of differing time periods for ascertaining risk such as the 'ever presented/admitted' in the life course (subject to data availability) as a way to capture a measure of lifelong risk as well as during the immediate study period. Our assessment of the relationship between the availability of culturally secure services and child health outcomes in this study will be limited to four regions of WA; this work could be extended in future research.

In summary, the Defying the Odds study expects to elucidate hidden variation in early childhood health outcomes for Aboriginal Western Australians. In addition, it will quantify the effects of health and social risk of earlier generations on the outcomes of the current generation in early childhood in order to inform service development and funding allocation on a needs basis for Aboriginal children and their families.

\section{Author affiliations}

${ }^{1}$ Aboriginal Health, Baker Heart and Diabetes Institute, Melbourne, Victoria, Australia ${ }^{2}$ Centre for Big Data Research in Health, University of New South Wales, Kensington, New South Wales, Australia

${ }^{3}$ School of Population and Global Health, University of Western Australia, Perth, Western Australia, Australia

${ }^{4}$ Faculty of Health Services, Curtin University of Technology—Shenton Park Campus, Perth, Western Australia, Australia

${ }^{5}$ National Centre for Epidemiology and Population Health, Australian National University, Canberra, Australian Capital Territory, Australia

${ }^{6}$ Telethon Kids Institute, West Perth, Western Australia, Australia

${ }^{7}$ School of Biomedical Sciences, University of Western Australia, Perth, Western Australia, Australia

Acknowledgements This manuscript does not necessarily reflect the views of the government departments involved in this research. Thank you to the Aboriginal and Torres Strait Islander people of Western Australia for the use of their health and administrative data. We acknowledge and thank the Western Australian Data Linkage Branch, WA Department of Health and the data custodians for their assistance in providing the linked data for the study. We acknowledge the excellent partnership between the Developmental Pathways in WA Children Project (Telethon Kids Institute), the Department of Health WA, and Department of Communities Child Protection and Family Support (formerly the Department for Child Protection and Family Support). We thank the services and organisations involved in the health and social services research to date and the participants for their time and shared expertise. We also thank our Aboriginal colleagues and community members, and the Western Australian Aboriginal Health Ethics Committee for their guidance on the study and the questionnaire development.

Collaborators Stephen Ball, Bridgid O'Brien, Fiona Stanley, James Ward, Robyn Williams

Contributors All authors (BM, LG, LJ, DP, JJ, GJ, CS, DM, SE) conceived the study, and devised and revised the protocol and manuscript. BM drafted the manuscript. All authors and named Defying the Odds Study investigators (alphabetically: Stephen Ball, Bridgid O'Brien, Fiona Stanley, James Ward, Robyn Williams) have been involved in planning, obtaining study funding, community engagement and/or beginning data collection.

Funding Funding for the Defying the Odds study has been provided by National Health and Medical Research Council of Australia (project grant 1078214). BM was supported by a National Health and Medical Research Council of Australia Training Fellowship (586736). Baker Heart and Diabetes Institute is supported in part by the Victorian Government OIS Programme.

Competing interests None declared.

Patient consent Obtained.

Ethics approval Western Australian Aboriginal Health Ethics Committee, Western Australian Department of Health HREC, Western Australian Country Health Services HREC, Alfred Health HREC.

Provenance and peer review Not commissioned; peer reviewed for ethical and funding approval prior to submission.

Open Access This is an Open Access article distributed in accordance with the Creative Commons Attribution Non Commercial (CC BY-NC 4.0) license, which permits others to distribute, remix, adapt, build upon this work non-commercially, and license their derivative works on different terms, provided the original work is properly cited and the use is non-commercial. See: http://creativecommons.org/ licenses/by-nc/4.0/

(c) Article author(s) (or their employer(s) unless otherwise stated in the text of the article) 2018. All rights reserved. No commercial use is permitted unless otherwise expressly granted.

\section{REFERENCES}

1. Al-Yaman F. The Australian Burden of Disease Study: impact and causes of illness and death in Aboriginal and Torres Strait Islander people, 2011. Public Health Res Pract 2017;27. 
2. Falster $\mathrm{K}$, Banks $\mathrm{E}$, Lujic $\mathrm{S}$, et al. Inequalities in pediatric avoidable hospitalizations between Aboriginal and non-Aboriginal children in Australia: a population data linkage study. BMC Pediatr 2016;16:169.

3. McAuley K, McAullay D, Strobel NA, et al. Hospital utilisation in indigenous and non-indigenous infants under 12 months of age in Western Australia, prospective population based data linkage study. PLoS One 2016;11:e0154171.

4. Australian Institute of Health and Welfare. Hospitalised injury in children and young people 2011-12. Canberra: AlHW, 2014

5. Read AW, Gibbins J, Stanley FJ, et al. Hospital admissions before the age of 2 years in Western Australia. Arch Dis Child 1994;70:205-10.

6. Dudgeon P, Wright M, Paradies Y, et al. Aboriginal social, cultural and historical contexts (chapter 1). In: Dudgeon P, Milroy H, Walker $\mathrm{R}$, eds. Working together: Aboriginal and Torres Strait Islander mental health and wellbeing principles and practice. Canberra: Commonwealth of Australia, 2014.

7. Atkinson J, Nelson J, Brooks R, et al. Addressing individual and community transgenerational trauma (chapter 17). In: Dudgeon $\mathrm{P}$, Milroy $\mathrm{H}$, Walker R, eds. Working together: Aboriginal and Torres Strait Islander mental health and wellbeing principles and practice. Canberra: Commonwealth of Australia, 2014.

8. Urquhart B. Summary of selected social indicators. Australia: Australian Indigenous HealthInfoNet, 2009. http://www.healthinfonet. ecu.edu.au/determinants/social-issues/reviews/selected-socialindicators (accessed 3 Aug 2017).

9. Meuleners LB, Lee AH, Hendrie D, et al. A population study on indigenous hospitalisations for interpersonal violence. Aust Health Rev 2010;34:123-6.

10. Burns L, Black E, Powers JR, et al. Geographic and maternal characteristics associated with alcohol use in pregnancy. Alcohol Clin Exp Res 2011;35:1230-7.

11. Burns L, Mattick RP, Cooke M. Use of record linkage to examine alcohol use in pregnancy. Alcohol Clin Exp Res 2006;30:642-8.

12. O'Leary CM, Halliday J, Bartu A, et al. Alcohol-use disorders during and within one year of pregnancy: a population-based cohort study 1985-2006. BJOG 2013;120:744-53.

13. O'Leary C, Jacoby P, D'Antoine $\mathrm{H}$, et al. Heavy prenatal alcohol exposure and increased risk of stillbirth. BJOG 2012;119:945-52.

14. Halfon N, Hochstein M. Life course health development: an integrated framework for developing health, policy, and research. Milbank Q 2002;80:433-79.

15. McEwen BS. Protective and damaging effects of stress mediators. $N$ Engl J Med 1998;338:171-9.

16. Irwin L, Siddiqi A, Hertzman C. World Health Organization's Commission on the Social Determinants of Health Final Report; Early Child Development: A Powerful Equalizer. Geneva: World Health Organization, 2007.

17. Government of Australia. National Aboriginal and Torres Strait Islander Health Plan 2013-2023. Canberra: Commonwealth of Australia, 2013.

18. Australian Government. Closing the gap: target and building blocks. 2008 http://www.dss.gov.au/our-responsibilities/ indigenous-australians/programs-services/closing-the-gap/ closing-the-gap-targets-and-building-blocks (accessed 13 Jan 2014).

19. National Aboriginal Community Controlled Health Organisation (NACCHO). Aboriginal Health Definitions. 2017 (accessed 7 Aug 2017)

20. Bronfenbrenner U. The ecology of human development: experiments by nature and design. Cambridge, Massachusetts: Harvard University Press, 1979

21. TftARAfCaY M. Early childhood and long term development: the importance of the early years. Melbourne: Murdoch Children's Research Centre, Royal Children's Hospital, 2006.

22. Zubrick S, Lawrence D, Silburn S, et al; The Western Australian Aboriginal Child Health Survey: the health of Aboriginal children and young people. Perth: Telethon Institute for Child Health Research, 2004.

23. Department of Families Housing Community Services and Indigenous Affairs. Footprints in time: the longitudinal study of indigenous children-key summary report from wave 1. Canberra: FaHCSIA, 2009.

24. Shepherd CC, Li J, Zubrick SR. Social gradients in the health of Indigenous Australians. Am J Public Health 2012;102:107-17.

25. Habibis $\mathrm{D}$, Taylor $\mathrm{P}$, Walter $\mathrm{M}$, et al. Repositioning the racial gaze: Aboriginal perspectives on race, race relations and governance. Social Inclusion 2016;4:57-67.

26. ABS. Estimates of Aboriginal and Torres Strait Islander Australians. Canberra: Australian Bureau of Statistics, 2011.

27. Clark $A$, Preen $D B, N g ~ J Q$, et al. Is Western Australia representative of other Australian States and Territories in terms of key socio- demographic and health economic indicators? Aust Health Rev 2010;34:210-5.

28. Christensen D, Davis G, Draper G, et al. Evidence for the use of an algorithm in resolving inconsistent and missing Indigenous status in administrative data collections. Aust J Soc Issues 2014;49:423-43.

29. Holman CD, Bass AJ, Rouse IL, et al. Population-based linkage of health records in Western Australia: development of a health services research linked database. Aust N Z J Public Health 1999;23:453-9.

30. Government of Western Australia. Data linkage-making the right connections. Perth: Department of Health, Government of Western Australia, 2016

31. Glasson EJ, de Klerk NH, Bass AJ, et al. Cohort profile: the Western Australian Family Connections Genealogical Project. Int J Epidemiol 2008;37:30-5.

32. Sprivulis P, Da Silva JA, Jacobs I, et al. ECHO: the Western Australian Emergency Care Hospitalisation and Outcome linked data project. Aust N Z J Public Health 2006;30:123-7.

33. NHDC. National health data dictionary, Version 12. Canberra: National Health Data Committee, Australian Institute of Health and Welfare, 2003.

34. ABS. Demographic, social and economic characteristics overview: life expectancy. Canberra: Australian Bureau of Statistics, 2010.

35. Scrimgeour M, Scrimgeour D. Health care access for Aboriginal and Torres Strait Islander people living in urban areas, and related research issues: a review of the literature. Darwin: Cooperative Research Centre for Aboriginal Health, 2007.

36. Thompson SC, Woods JA, Katzenellenbogen JM. The quality of indigenous identification in administrative health data in Australia: insights from studies using data linkage. BMC Med Inform Decis Mak 2012;12:133.

37. Australian institute of Health and Welfare. National best practice guidelines for data linkage activities relating to Aboriginal and Torres Strait Islander people. Canberra: AlHW, 2012. AlHW Cat. No. IHW 74.

38. Beal SM. Sudden infant death syndrome in South Australia 1968-97. Part I: changes over time. J Paediatr Child Health 2000;36:540-7.

39. Oddy WH, Kickett-Tucker C, De Maio J, et al. The association of infant feeding with parent-reported infections and hospitalisations in the West Australian Aboriginal Child Health Survey. Aust N Z J Public Health 2008:32:207-15.

40. Jama-Alol KA, Moore HC, Jacoby P, et al. Morbidity due to acute lower respiratory infection in children with birth defects: a total population-based linked data study. BMC Pediatr 2014;14:80

41. Moore HC, de Klerk N, Richmond P, et al. A retrospective populationbased cohort study identifying target areas for prevention of acute lower respiratory infections in children. BMC Public Health 2010;10:757-65

42. Panaretto KS, Whitehall JF, McBride G, et al. Sudden infant death syndrome in Indigenous and non-Indigenous infants in north Queensland, 1990-1998. J Paediatr Child Health 2002;38:135-9.

43. Alsharif AT, Kruger E, Tennant M. Dental hospitalization trends in Western Australian children under the age of 15 years: a decade of population-based study. Int J Paediatr Dent 2015;25:35-42.

44. Slack-Smith LM, Read AW, Colvin LJ, et al. Total population investigation of dental hospitalizations in indigenous children under five years in Western Australia using linked data. Aust Dent $J$ 2011;56:358-64.

45. Nugent AW, Daubeney PE, Chondros P, et al. The epidemiology of childhood cardiomyopathy in Australia. N Engl J Med 2003;348:1639-46

46. Lee $\mathrm{AH}$, Flexman J, Wang $\mathrm{K}$, et al. Recurrent gastroenteritis among infants in Western Australia: a seven-year hospital-based cohort study. Ann Epidemiol 2004;14:137-42.

47. Cresp R, Clarke K, McAuley KE, et al. Effectiveness of the Koorliny Moort out-of-hospital health care program for Aboriginal and Torres Strait Islander children in Western Australia. Med J Aust 2016;204:197.

48. Wallis BA, Watt K, Franklin RC, et al. Drowning in Aboriginal and Torres Strait Islander children and adolescents in Queensland (Australia). BMC Public Health 2015;15:795.

49. O'Donnell $\mathrm{M}$, Nassar $\mathrm{N}$, Leonard $\mathrm{H}$, et al. Monitoring child abuse and neglect at a population level: patterns of hospital admissions for maltreatment and assault. Child Abuse Negl 2010;34:823-32.

50. Möller H, Falster K, Ivers R, et al. Inequalities in hospitalized unintentional injury between Aboriginal and non-Aboriginal children in New South Wales, Australia. Am J Public Health 2016;106:899-905.

51. Valery PC, Youlden DR, Baade PD, et al. Cancer survival in Indigenous and non-Indigenous Australian children: what is the difference? Cancer Causes Control 2013;24:2099-106.

52. Moore H, Burgner D, Carville K, et al. Diverging trends for lower respiratory infections in non-Aboriginal and Aboriginal children. $J$ Paediatr Child Health 2007:43:451-7. 
53. Jamieson LM, Roberts-Thomson KF. Indigenous children and receipt of hospital dental care in Australia. Int $J$ Paediatr Dent 2006;16:327-34.

54. Irie F, Lang J, Kaltner M, et al. Effects of gender, indigenous status and remoteness to health services on the occurrence of assaultrelated injuries in children and adolescents. Injury 2012;43:1873-80.

55. Rotte L, Hansford J, Kirby M, et al. Cancer in Australian Aboriginal children: room for improvement. J Paediatr Child Health 2013;49:27-32.

56. Freemantle CJ, Read AW, de Klerk NH, et al. Sudden infant death syndrome and unascertainable deaths: trends and disparities among Aboriginal and non-Aboriginal infants born in Western Australia from 1980 to 2001 inclusive. J Paediatr Child Health 2006;42:445-51.

57. Kolos V, Menzies R, Mclntyre P. Higher pertussis hospitalization rates in indigenous Australian infants, and delayed vaccination. Vaccine 2007;25:588-90.

58. O'Grady KA, Lee KJ, Carlin JB, et al. Increased risk of hospitalization for acute lower respiratory tract infection among Australian indigenous infants 5-23 months of age following pneumococcal vaccination: a cohort study. Clin Infect Dis 2010;50:970-8.

59. Gracey M, Cullinane J. Gastroenteritis and environmental health among Aboriginal infants and children in Western Australia. $J$ Paediatr Child Health 2003;39:427-31.

60. Lee AH, Gracey M, Wang K, et al. Under-nutrition affects time to recurrence of gastroenteritis among Aboriginal and non-Aboriginal children. J Health Popul Nutr 2006;24:17-24.
61. Lee $\mathrm{AH}$, Wang K, Gracey M, et al. Factors affecting length of hospitalization of infants and children for recurrent gastroenteritis in Western Australia. Acta Paediatr 2003;92:843-7.

62. Wang K, Yau KK, Lee AH. Factors influencing hospitalisation of infants for recurrent gastroenteritis in Western Australia. Methods Inf Med 2003;42:251-4.

63. Caffery L, Bradford N, Meurer M, et al. Association between patient age, geographical location, Indigenous status and hospitalisation for oral and dental conditions in Queensland, Australia. Aust J Prim Health 2017;23:46-52.

64. Kruger E, Dyson K, Tennant M. Hospitalization of Western Australian children for oral health related conditions: a 5-8 year follow-up. Aust Dent J 2006;51:231-6.

65. O'Grady KA, Taylor-Thomson DM, Chang AB, et al. Rates of radiologically confirmed pneumonia as defined by the World Health Organization in Northern Territory Indigenous children. Med J Aust 2010;192:592-5.

66. O'Grady KA, Torzillo PJ, Chang AB. Hospitalisation of Indigenous children in the Northern Territory for lower respiratory illness in the first year of life. Med J Aust 2010;192:586.

67. Moore HC, Manoharan KR, Lim FJ, et al. Diverging trends in gastroenteritis hospitalizations during 2 decades in western Australian Aboriginal and non-Aboriginal children. Pediatr Infect Dis J 2013;32:1169-74.

68. Yau KK, Lee AH, Gracey M. Multilevel modelling of hospitalisations for recurrent diarrhoeal disease in Aboriginal and non-Aboriginal infants and young children in Western Australia. Paediatr Perinat Epidemiol 2005;19:165-72. 